University for Business and Technology in Kosovo

UBT Knowledge Center

Oct 27th, 3:15 PM - 4:45 PM

\title{
Side Effects of Metoclopramide (Reglan) Oral Overdose in Pediatric Patients
}

\author{
Edmont Laho \\ Medical Hospital Center Elbasan, Albania, lahoe90@gmail.com \\ Xhejni Borshi \\ Albanian University, Tirana
}

Follow this and additional works at: https://knowledgecenter.ubt-uni.net/conference

Part of the Medicine and Health Sciences Commons

\section{Recommended Citation \\ Laho, Edmont and Borshi, Xhejni, "Side Effects of Metoclopramide (Reglan) Oral Overdose in Pediatric Patients" (2018). UBT International Conference. 375. \\ https://knowledgecenter.ubt-uni.net/conference/2018/all-events/375}

This Event is brought to you for free and open access by the Publication and Journals at UBT Knowledge Center. It has been accepted for inclusion in UBT International Conference by an authorized administrator of UBT Knowledge Center. For more information, please contact knowledge.center@ubt-uni.net. 


\title{
Side effects of metoclopramide (Reglan) oral overdose in pediatric patients
}

\author{
Edmont Laho ${ }^{1,}$,Xhejni Borshi $^{2}$, Indrit Bimi ${ }^{3}$, Eti Muharremi $^{4}$ \\ ${ }^{1}$ Department of pediatrics, Medical hospital center Elbasan,Albania \\ Albanian University, Tirana, Albania \\ ${ }^{2}$ The head of the Deparatment of Physiotherapy and Nursing \\ Albanian University, Tirana, Albania \\ ${ }^{3}$ The pedagogue of the Deparatment of Physiotherapy and Nursing \\ “Aleksander Mosiu”University, Durres,, Albania \\ ${ }^{4}$ General physician Public Healthy Regional Directory, Elbasan \\ Email: lahoe90@gmail.com
}

\begin{abstract}
Drugs like metoclopramide are used in pediatric patients for the treatment of frequent vomiting or gastrointestinal disorders especially at the age of three. The most common use is Reglan solution, but its dose should be strictly observed because of low therapeutic index overdose is easily achieved, manifesting with extrapyramidal side effects.

The purpose of the study is to detect the frequent side-effects of the extrapyramidal nervous system that are due to the oral overdose of Reglan in the pediatric population.

Materials and methods. This study analyzed all the cases of Metoclopramide toxicity who took the Reglan solution in an outpatient setting and were then diagnosed and treated in the Pediatric Service in the Hospital of Elbasan during January 2014 to December 2016 period. These cases have been treated in the Pediatric Service in Elbasan. After having been diagnosed with signs of the nervous system from the overdose of Reglan solution they were surveyed in terms of dose taken, duration of use, age, etc.

Results. The17 cases diagnosed in our service varied in clinical presentation from nuchal rigidity to whole body contractions and somnolence. Out of these, nine children were younger than 1 year old, 5 children 1-4 years old, and 3 children were aged 4-8 years. All the children younger than one received Reglan solution at high doses 3 times 1 coffee spoon (also fivefoldtenfold of the dose) while the therapeutic dose for Reglan solution is $0.1 \mathrm{mg} / \mathrm{kg}$ in $3-4$ doses.

Conclusions. Considering this medication has a low therapeutic index, cautions to prescribe and administer the right dose are of the upmost importance. As a result, the general practitioner and the pharmacists should be instructed that children younger than 1 year old should not take this medication and if need be and there are no other alternatives it should be administered with drops and not with coffee spoon $(2.5 \mathrm{ml})$ or jam spoon $(5 \mathrm{ml})$.
\end{abstract}

Key words: vomiting, dosage, reflux, reglan, drops 


\section{Introduction}

Metoclopramide is a Dopamine receptor antagonist. Metoclopramide has antiemetic, antinauseant and gastrokinetic activity. It stimulates motility of the upper gastrointestinal tract without stimulating gastric, biliary or pancreatic secretions. The rate of gastric emptying is increased due to increased peristalsis of the jejunum and duodenum. The tone and amplitude of gastric contractions are increased, with relaxation of the pyloric sphincter and duodenal bulb. These effects combine to result in decreased intestinal transit time, making a good anti emetic. The effect of metoclopramide on motility is not dependent on intact vagal innervation, but it can be abolished by anticholinergic drugs. Metoclopramide has little, if any, effect on the motility of the colon or bladder. Metoclopramide also exhibits dopamine antagonist activity and consequently produces sedation and, rarely, other extrapyramidal reactions.

It was firstly used by an American physician in 1964 and it has since been used all over the world. Metoclopramide is one of the 100 most used drugs in the last ten years in USA. It has also made the list of Essential drugs of World Health Organization (WHO) [1].

The structural formula is:

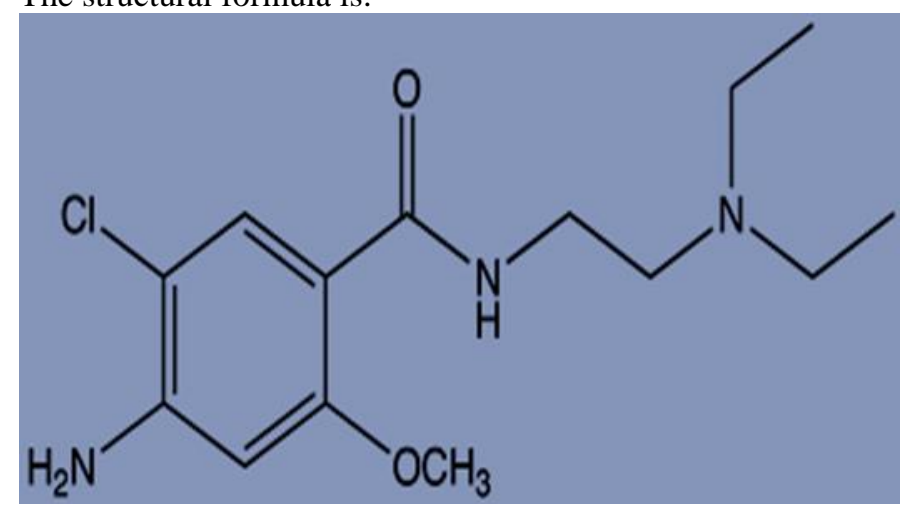

Metoclopramide is sold under the trade name Reglan or Primepran and it is widely used for gastrointestinal disturbances, hiatal hernia, biliary stones, gastritis and gastric ulcers. This drug is used to control nausea, stomach ache and upper abdominal pain [2].. In our clinical experience we have witnessed a very high efficacy of this drug in controlling the vomiting of different causes and makes a great choice in diabetics with vomiting due to gastroparesis. Metoclopramide is used in surgery to control the postoperative vomiting.

Metoclopramide is also used in pediatric patients to control vomiting due to gastroenteritis or enteroviral infections. It is essential to administer the correct dossage due to risky side effects seen with its toxicity. This drug is also used to control vomiting associated with radiation therapy or intolerance to cytotoxic drug or 
used preoperatively to stop the vomiting during surgery and also assists in small bowel intubation [3]..

\section{Dossage and administration}

- Adults 20 years and over: Maximum of $10 \mathrm{mg}$ three times a day.

- Children: Treatment of children should commence at the lower dosage of $0.1-0.15 \mathrm{mg} / \mathrm{kg}$ three times a day or as a solution $5 \mathrm{mg} / 5 \mathrm{ml}$ a clear, colourless, sterile, preservative-free solution containing metoclopramide hydrochloride anhydrous used to come with a dropper (Primepran) [4].

Parenteral forms (I.V. or I.M.) are $10 \mathrm{mg} / 2 \mathrm{ml}$. This is recomended in patients with extensive vomiting, after the patient is firstly hydrated with Ringer's solution or Sodium Chloride $0.9 \%$ [5].

\section{Side effects}

Tardive dyskinesia may appear in some patients on long-term therapy or may appear after drug therapy has been discontinued. The risk appears to be greater in pediatric patients on high dose therapy. The symptoms are persistent and can often at times appear to be irreversible. The syndrome is characterized by rhythmical involuntary movement of the tongue, face, mouth or jaw (e.g. protrusion of tongue, puffing of cheeks, puckering of mouth, chewing movements). Sometimes these may be accompanied by involuntary movement of extremities. The frequency and severity of seizures or extrapyramidal reactions may be increased in epileptic patients given metoclopramide. Dystonic reactions occur in approximately $1 \%$ of patients given metoclopramide [6]. These occur more often in children and young adults and may occur after a single dose. Neuroleptic malignant syndrome has been reported when metoclopramide has been used alone or in combination with neuroleptics. Metoclopramide elevates prolactin levels. This may be of importance in patients with previously detected breast cancer, in which the breast cancer is prolactin dependent. Because of prolactin elevation it presents with disturbances such as galactorrhea, amenorrhea, gynecomastia and impotence in men. Because of its cholinomimetic properties and because it decreases intestinal transit time this drug may induce diarrhea.

The purpose of this study is to evident the extrapyramidal side effects and other side effects related to Metoclopramide (Reglan) toxicity after oral or parenteral administration in pediatric population.

\section{Patients and methods}


This study analyzed all the cases of Metoclopramide toxicity diagnosed and treated in the Pediatric Hospital of Elbasan during January 2014 to December 2016 period. The cases were then classified regarding the epidemiologic criteria, the dosage administered to the patient, the time the patient was on the drug, the coexistence of other pathologies and socio-demographic variables like: age, residency.

\section{Results}

There were 17 cases in total diagnosed in the Pediatric Hospital of Elbasan. Their clinical symptoms varied from neck rigidity to whole body contractions and somnolence. Some of the children had "facial mask" or facial spasms. Patients aged older than 3 years old could not talk and they exhibit uncontrollable movements of the extremities and they fell whenever they tried to walk.

9 of the 17 children were younger than 1 year of age, 5 children were 1-4 years of age and 3 were $4-8$ years old.

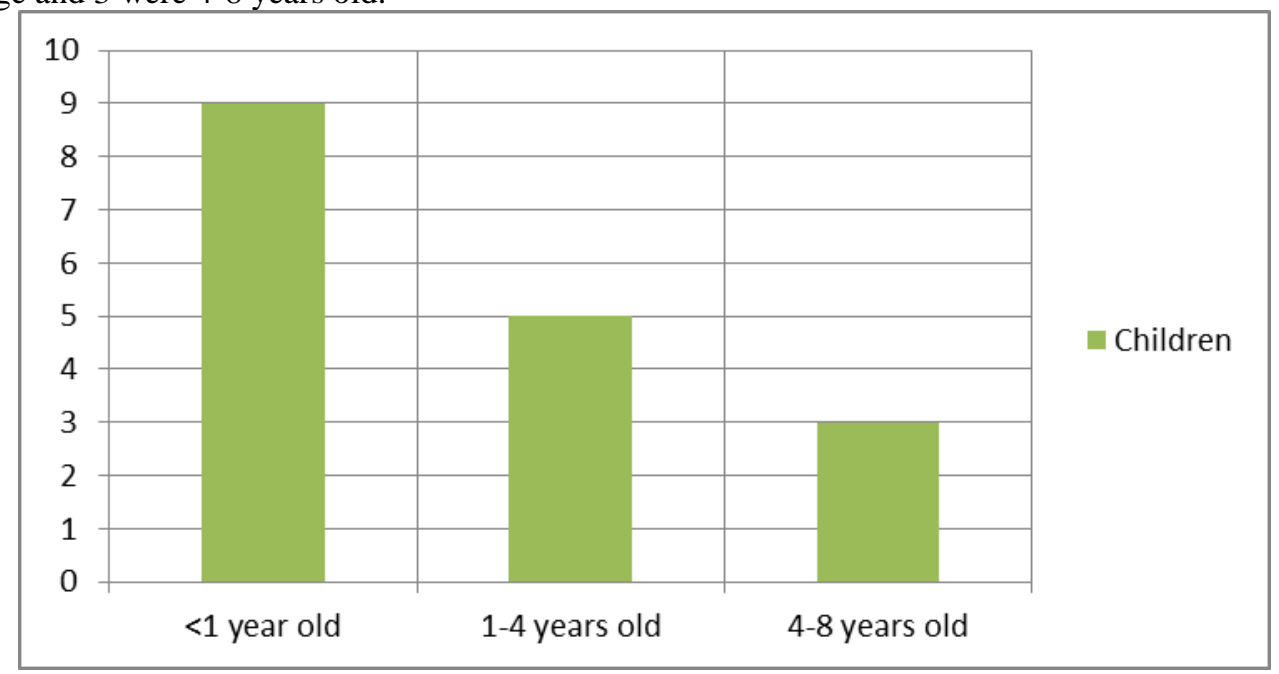

Graph 1: Children classified by age group.

All the children younger than 1 year old were administered Reglan solution 5-10 times ( 3 times 1 coffee spoon) the allowed dose of $0.1 \mathrm{mg} / \mathrm{kg} 3$ times a day.

Regarding their place of residence: 11 children were located in rural areas while only 6 were located in urban areas. 


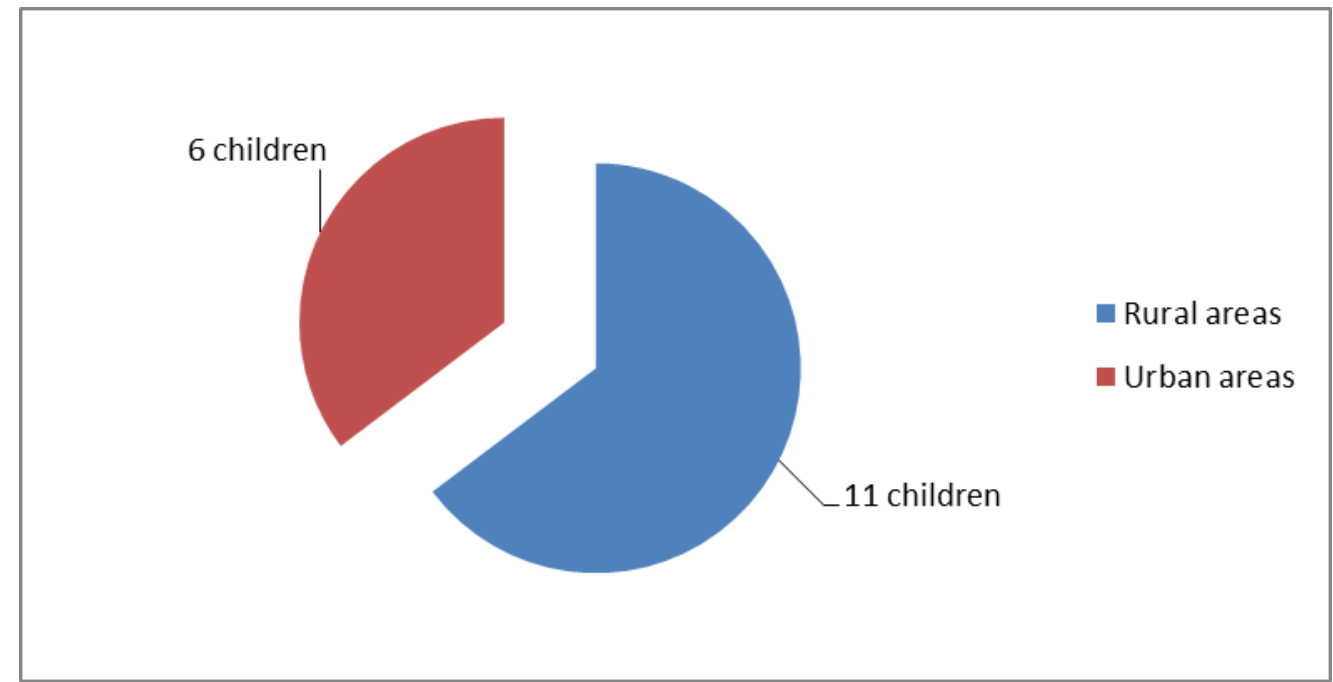

Graph 2: Place of residence of children who were intoxicated with Metoclopramide.

Regarding the pathology the children first came for in the clinic for which they took Metoclopramide: 6 were diagnosed as Enteroviral infection, 7 cases of Gastroenteritis and 4 of Gastroesophageal reflux (GERD).

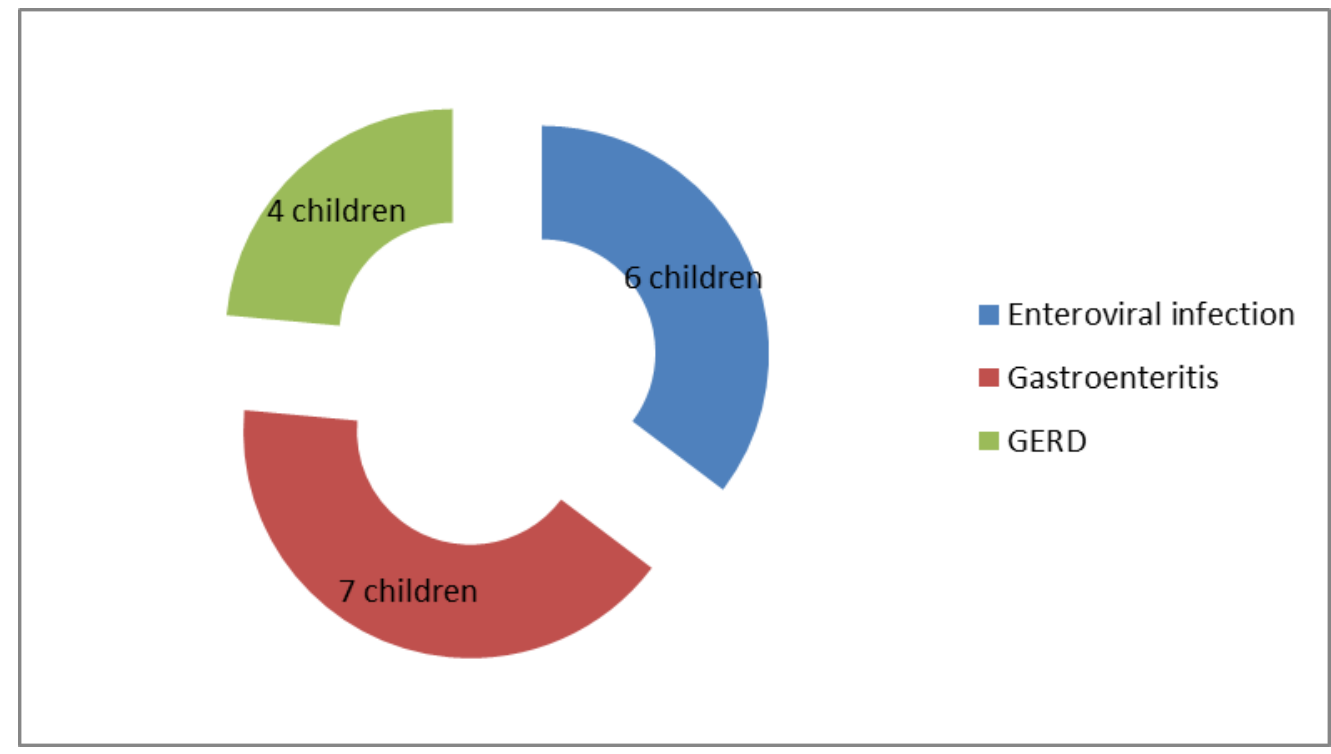

Graph 3: Divided by the pathology the children first came for in the clinic for which they took Metoclopramide 
In our study we analyzed the cases of Metoclopramide (Reglan) toxicity considering the timeline of emerging side effects. In children younger than 1 year of age the first signs of intoxication started during the second day (after the first 24h) of taking the medication. Six out of nine of these cases had a severe clinical manifestation with extrapyramidal signs because of taking the medication in doses of 4-5 ml.

\section{Discussion}

Side effects from metoclopramide (Reglan) toxicity are fairly often in the clinical practice compared to other medications. The most cases are reported in pediatric population. This is illustrated on Graphic 1 where more than $60 \%$ of the cases included in this study are $0-1$ years of age. Infants are poisoned with this medication, receiving a dose greater than the maximal daily dose of $0.3 \mathrm{mg} / \mathrm{kg}(0.1-0.15 \mathrm{mg} / \mathrm{kg}$ taken 2-3 times a day) [7]. A $7 \mathrm{~kg}$ child should not be administered more than 10-15 drops per day ( $0.7 \mathrm{ml} \mathrm{2-3} \mathrm{times} \mathrm{a} \mathrm{day).} \mathrm{In} \mathrm{this} \mathrm{study} \mathrm{we} \mathrm{found} \mathrm{out} \mathrm{that} \mathrm{many} \mathrm{children}$ have received the medication 2-3 times per day up to 4-5 ml, making it an overdose. In this situation the children were presented to the Emergency Room with the extrapyramidal symptoms described above [8]. This mistake occurs due to a miscommunication between the physician and pharmacist, the latter one being responsible a lot of times for selling medications without prescription or misreads the correct dosage of the medication.

The risk is increased because in our country Metoclopramide that is sold under the trade name Reglan lacks a dropper. A few years ago Primeran solution was widely available in the drug market in Albania. It had a dropper that helped avoiding mistakes in dossing administration.

In this study we found that most of the cases were from rural centers. This not only shows the problems and the shortcoming of specialized doctors in these zones but also the lack of medical knowledge in the population. In two cases after the children, respectively 4 and 7 years of age, were still vomiting after taking Reglan, the medical personnel administered Primepran (I.M.) too. Another added risk factor we came through was the non-administration of Ringer or Glucose solution to treat the dehydration after taking Reglan. Certain authors emphasize the contraindication of Metoclopramide in infants ( $<1$ year old) because of the side effects [9] [10].

In recent years even though there is an increase in other anti-emetics like Domperidone or Ranitidine to treat the acutely ill patients, Metoclopramide still remains the most preferred due to best efficacy in clinical setting even though the literature suggests that there are no differences in efficacy between Domperidone and Metoclopramide. Domperidone is suggested to be used more due to its safer profile [11].

Ondansetron, a serotonin 5HT-3 antagonist, FDA approved for children older than 1 month of age (earlier than any of the other medications discussed above). Scientific evidence support the use of Ondansetron in children that present with vomiting [12]. It is the only antiemetic for which there are randomized, controlled trials that support its use. A meta-analysis from DeCamp et al., all the children who were administered Ondansetron were less predisposed to have ongoing vomiting, need for I.V. fluids or 
hospitalization. In Europe Ondansetron is available in 16 countries under the trade name Setofilm in $4 \mathrm{mg}$ and $8 \mathrm{mg}$ doses [13] [14].

Patient and parents experience these sudden and rapidly accelerated symptoms very dramatically making it very hard to get an anamnesis.

One other study from LC Low and K M Goel observed 15 children with metoclopramide (MaxoIon) poisoning. One of the 5 children accidentally poisoned developed slight extrapyramidal signs. All 10 children who experienced extrapyramidal side effects while being treated with metoclopramide had received a dose greater than that recommended by the manufacturer of $0,5 \mathrm{mg} / \mathrm{kg}$ per day [15]. Dystonic reactions are likely to occur if the recommended dose is exceeded, but individual susceptibility to metoclopramide and the cumulative effect of repeated doses of the drug may also be important. Similar reasons were identified in our study.

\section{Conclusions}

Side effects from Reglan solution (Metoclopramide) are common in pediatric population and happen due to mistakes in dosing. Considering this medication has a low therapeutic index, cautions to prescribe and administer the right dose are of the upmost importance. As a result, the general practitioner and the pharmacists should be instructed that children younger than 1 year old should not take this medication and if need be and there are no other alternatives it should be administered with drops and not with coffee spoon $(2.5 \mathrm{ml})$ or jam spoon $(5 \mathrm{ml})$.

A healthy professional interaction between the physician, the pharmacist and the nursing staff is very important in order to elude the mistakes in the future. Medical personnel should be advised to not administer Metoclopramide P.O. or I.M. before starting fluids in order to hydrate the patient when dehydration is present. After the electrolyte balances are controlled lowering the risk of side effects, the patient can be administered Metoclopramide to control the vomiting.

\section{References}

1. European Medicines Agency recommends changes to the use of metoclopramide, 2013.

2. Sedat Işıkay, Kutluhan Yılmaz, Mehmet Almacıoğlu (2013) Evaluation of Patients with Metoclopramide-Induced Acute Dystonic Reaction. JAEM 12: $80-84$

3. Selda Hizel Bulbul,Emine Dibek Misirlioglu,Erennur Tufan,Olcay Evliyaoglu (2010) Side Effects of Metoclopramide: Does It Deserve to Prescribe For Nausea,Vomiting? The New Journal of Medicine 27: 8486.

4. Witzel K. Extrapyramidal-motorische Störungen bei Kindern als Nebenwirkung der Therapie mit Neuroleptica und dem neuen Antiemeticum Metoclopramid. Arch Kinderheilkd. 1968 Sep;177(3):277283. [PubMed] 
5. Casteels-Van Daele M, Jaeken J, Van der Schueren P, Van den Bon P. Dystonic reactions in children caused by metoclopramide. Arch Dis Child. 1970 Feb;45(239):130-133. [PMC free article][PubMed]

6. Fournier A, Pauli A, Ducoulombier H, Cousin J. Effets du surdosage en méthoclopramide chez l'enfant. A propos de 9 observations cliniques. Pediatrie. 1969 Oct-Nov;24(7):799-805. [PubMed]

7. Cousin J, Katende C, Pauli A, Fournier A. L'intoxication par le Métoclopramide chez l'enfant. Nouv Presse Med. 1972 Aug 26;1(30):1995-1995. [PubMed]

8. Sedat Iş̧kay, Mehmet Almacıoğlu, Kutluhan Yılmaz (2012) Metoclopramide Induced Acute Dystonic Reaction in a Child: A Case Report. JAEMCR 3(2): 59-61.

9. Sills JA, Glass EJ. Metoclopramide in young children. Br Med J. 1978 Aug 5;2(6134):431-431.[PMC free article] [PubMed]

10. Bateman DN, Davies DS. Pharmacokinetics of metoclopramide. Lancet. 1979 Jan 20;1(8108):166-166. [PubMed]

11. LC K Low and K M Goel, Royal Hospital for Sick Children, Glasgow: Metoclopramide poisoning in children 1980

12. Strange GR, Ahrens WR, Lelyveld S, Schafermeyer RW. Pediatric emergency medicine: a comprehensive study guide. 2nd ed. Toronto, Ont: McGraw-Hill; 2002. pp. 347-352.

13. 2. Canadian Paediatric Society, Nutrition Committee. Oral rehydration therapy and early refeeding in the management of childhood gastroenteritis. Can J Ped. 1994;1:160-164.

14. 3. Burkhart DM. Management of acute gastroenteritis in children. Am Fam Physician. 1999;60(9):2555-2563. [PubMed]

15. 4. Kwon KT, Rudkin SE, Langdorf MI. Antiemetic use in pediatric gastroenteritis: a national survey of emergency physicians, pediatricians, and pediatric emergency physicians. Clin Pediatr (Phila) 2002;41(9):641652. [PubMed] 